\title{
Pediatric Age Palm Oil Consumption
}

\author{
Lorenza Di Genova, Laura Cerquiglini, Laura Penta, Anna Biscarini and Susanna Esposito \\ Pediatric Clinic, Department of Surgical and Biomedical Sciences, Università degli Studi di Perugia, \\ 06132 Perugia, Italy; lory.digenova@gmail.com (L.D.G.); laura.cerquiglini@ospedale.perugia.it (L.C.); \\ laura.penta@ospedale.perugia.it (L.P.); anna.biscarini@ospedale.perugia.it (A.B.) \\ * Correspondence: susanna.esposito@unimi.it; Tel.: +39-075-5784417; Fax: +39-075-5784415
}

Received: 12 February 2018; Accepted: 27 March 2018; Published: 1 April 2018

\begin{abstract}
Palm oil is widely used in the food industry for its chemical/physical properties, low cost and wide availability. Its widespread use has provoked an intense debate about whether it is a potential danger to human health. In a careful review of the scientific literature, we focused on nutritional characteristics and health effects of the use of palm oil with regards to children, seeking to determine whether there is evidence that justifies fears about the health effects of palm oil. Our review showed that palm oil represents a significant source of saturated fatty acids, to which scientific evidence attributes negative health effects when used in excess, especially with regards to cardiovascular diseases. However, to date, there is no evidence about the harmful effects of palm oil on the health of children. Nevertheless, palm oil has possible ill health effects linked to its composition of fatty acids: its consumption is not correlated to risk factors for cardiovascular diseases in young people with a normal weight and cholesterol level; the elderly and patients with dyslipidaemia or previous cardiovascular events or hypertension are at a greater risk. Therefore, the matter is not palm oil itself but the fatty-acid-rich food group to which it belongs. The most important thing is to consume no more than $10 \%$ of saturated fatty acids, regardless of their origin and regardless of one's age. Correct information based on a careful analysis of the scientific evidence, rather than a focus on a singular presumed culprit substance, should encourage better lifestyles.
\end{abstract}

Keywords: palmitic acid; palm oil; saturated fatty acid; breast milk; cardiovascular disease; obesity; overweight

\section{Introduction}

Palm oil is characterized by chemical/physical properties, low cost and wide availability and for these reasons is largely used in the food industry $\mathrm{r}$ [1-6]. However, there has been an intense debate about whether it is a potential danger to human health [1,7-16]. In 2016, the European Food Safety Authority (EFSA) produced a document on the risks related to the consumption of refined vegetable oils. In particular, the Panel on Contaminants in the Food Chain (CONTAM) warned of the presence of substances formed during the production process, particularly when vegetable oils are refined at high temperatures (approximately $200^{\circ} \mathrm{C}$ ); the oils undergo partial hydrolysis of triglycerides with glycerol oxidation, leading to the formation of 3-monochloropropanediol (3-MCPD) and 2-mono-chloropropanediol (2-MCPD) [1]. The highest levels of these compounds were observed in palm oil, but the majority of refined vegetable oils contain considerably large quantities. Interestingly, while refined palm oil might contain high amounts of MCPD, raw palm oil might be considered healthy.

In 2012, the Codex Alimentarius recommended the use of technological adjustments to reduce the levels of 3-MCPD in the finished product. In 2013, the International Agency for Research on Cancer (IARC) stated that there was no evidence to suggest that 3-MCPD is not genotoxic, and the same agency had already classified glycidol in the 2a group (i.e., probably carcinogenic to humans) in 
2000 [2]. In a careful review of the scientific literature, we focused on nutritional characteristics and health effects of the use of palm oil with regards to children, seeking to determine whether there is evidence that justifies fears about the health effects of palm oil.

\section{Materials and Methods}

This article provides an overview of papers regarding palm oil and child health in the past 20 years. A PubMed search indexed for MEDLINE and EMBASE was undertaken to identify studies in children and adults using the terms "palm oil", "palmitic acid", "saturated fatty acid", "health", "children", "cardiovascular diseases, "cholesterol", "postprandial lipemia", "diabetes", "inflammation", "cancer", "overweight" and "obesity" as key words. Only English-language articles were reviewed. The references of the selected articles were consulted for additional contributions that might be relevant. The date of our last search was August 2017, and the period covered was approximately 20 years.

\section{Palm Oil}

\subsection{Historical Notes, Biochemistry and the Role of Palm Oil in the Food Industry}

The first historical records related to human use of palm oil date back to five thousand years ago, when it played an essential role in the mummification process in Egypt [3]. Its use in manufacturing, including artisanal and industrial production, subsequently spread to Western Africa, Asia and, later, Europe. Its use for food purposes became considerable in the nineteenth century, when it became one of the most widely used vegetable oils in the food industry [3].

Palm oil is produced in tropical areas (Indonesia and Malaysia) and is derived from palm nuts. Its fat has a solid consistency at room temperature because of its elevated percentage of saturated fatty acids. The crude form is known as red palm oil for its coloration, which is derived from elevated concentrations of $\alpha$ - and $\beta$-carotenoids. In addition, the native form is rich in other antioxidants, including phytosterol and vitamin E (in the form of $\alpha$-tocopherol and tocotrienol), which protect the cellular membrane and influence platelet aggregation, modulating the synthesis of thromboxane. Palm oil was also shown to be an excellent oil source for delivering vitamin A in countries with high prevalence of vitamin A deficiency and malnutrition $[15,16]$. It could be demonstrated that the stability of vitamin A is much higher in palm oil than in soybean oil, which makes palm oil a superior vehicle in fortification programs. In Europe, palm oil is used after refinement, which strips it of carotenoids and similar antioxidant compounds.

Palm oil should not be confused with palm kernel oil, derived from palm seeds, which has a significantly higher concentration of saturated fatty acids [3]. Globally, palm oil is used as follows [4]: (1) $80 \%$ in the food industry (i.e., oil for frying, margarine, baking products, many processed foods); (2) $19 \%$ in cosmetics, soaps, lubricants, pharmaceuticals, lacquers and similar products; (3) $1 \%$ for the production of biodiesel. Crude palm oil is made up of almost $100 \%$ lipids, nearly all in the form of triglycerides. Saturated fatty acids (predominantly palmitic acid) constitute approximately $45 \%$ of its total fatty acids. The balance between saturated and monounsaturated plus polyunsaturated fatty acids (approximately 1:1) is nutritionally favourable.

The metabolic effects of palm oil are influenced by the stereospecific distribution of the different fatty acids: palmitic acid is esterified in the sn- 1 and sn- 3 positions of the glycerol in $87 \%$ the cases and in the sn-3 position approximately $12 \%$ of the time, while the unsaturated fatty acids (oleic and linoleic) are predominantly esterified in the sn-2 position. This particular distribution affects their intestinal absorption: fatty acids that are esterified in the sn- 1 and sn-3 positions are substrates of pancreatic lipase and are released in the intestinal tract. Fatty acids that are esterified in the sn- 2 position are instead absorbed efficiently, similar to monoglycerides, after hydrolysis of the fatty acids at sn- 1 and sn-3 [5].

The more efficient absorption of fatty acids esterified in the sn-2 position also explains the different absorption of the various fatty acids in breast milk versus bovine milk. Palmitic acid is the predominant saturated fatty acid in the human diet and is the most common saturated fat in breast milk. In contrast 
to bovine milk, breast milk contains a large quantity of palmitic acid esterified in the sn-2 position. This makes the absorption of palmitic acid easier for the nursling, which favours rapid growth in the first months of life [6,7].

Palm oil undergoing interesterification procedures has a nonselective distribution of saturated fatty acids in the sn-3 binding position of glycerol. After interesterification, palmitic acid is no longer selectively excreted in the faeces and is absorbed more efficiently owing to its presence in the sn-2 position. In the literature, palmitic acid esterified in the sn-2 position seems not to have direct effects on postprandial lipemia, glucose metabolism or insulin compared with palmitic acid esterified in sn-1 or sn-3 [8,9].

Potential critical objections to palm oil are derived mainly from the use of oil exposed to many heating and cooking cycles in industry and catering, since those conditions are conducive to the formation of oxidation products, which are unfavorable for the cardiovascular system $[7,10]$.

Currently, the food industry pays special attention to industrial transformation processes such as temperature, sudden changes in heat and pressure, and critical contamination levels of glucose fatty acids (GE), 3-MCPD, 2-MCPD and their esters to guarantee the quality of their products [1]. The same production companies are required to respect the environment by adhering to projects for the sustainability of palm oil, working together in national palm oil alliances.

\subsection{Possible Alternatives: Advantages and Disadvantages}

Food lipids are made up of glycerides, principally triglycerides. Saturated fatty acids, especially myristic, palmitic and stearic acids, are the main compounds of mammal fats, while polyunsaturated fats are prevalent in fish oils $[12,17,18]$. Cooking oils derived from vegetables contain lesser quantities of saturated fats. Oleic acid prevails in olive oil and linoleic acid in corn, sunflower, grape seed, and safflower oil. Coconut and palm kernel oil have notably higher quantities of saturated fats than other oils. Linoleic and linolenic acids are found in abundance in soybean oil [18]. Some vegetable oils, such as margarine, undergo many processes of hydrogenation that allow the polyunsaturated fatty acids to assume trans structures, losing their profile of metabolic safety (Table 1) [4,12].

Table 1. Different compositions of palm oil and other fats.

\begin{tabular}{ccccccccc}
\hline & Palm Oil & $\begin{array}{c}\text { Soybean } \\
\text { Oil }\end{array}$ & $\begin{array}{c}\text { Canola } \\
\text { Oil }\end{array}$ & $\begin{array}{c}\text { Sunflower } \\
\text { Oil }\end{array}$ & $\begin{array}{c}\text { Olive } \\
\text { Oil }\end{array}$ & $\begin{array}{c}\text { Coconut } \\
\text { Oil }\end{array}$ & Butter & Margarine \\
\hline Saturated fatty acids & $45-55$ & $11-21$ & $2-8$ & $10-16$ & $9-26$ & $55-75$ & $49-51$ & 28 \\
Lauric acid C12:0 & $0-0.5$ & $<0.2$ & $<0.2$ & $<0.2$ & $<0.05$ & $44-51$ & $2-4$ & $<0.2$ \\
Myristic acid C14:0 & $0.5-2$ & $<0.2$ & $<0.2$ & $<0.2$ & 0.05 & $13-18$ & 8 & $<0.2$ \\
Palmitic acid C16:0 & $39.5-47.5$ & $8-13$ & $1-5$ & $5-8$ & $7.5-20$ & $8-10$ & 21 & 20 \\
Stearic acid C18:0 & $3.5-6$ & $3-6$ & $1-2$ & $4-6$ & $0.5-6$ & 0.5 & 9 & 5 \\
Monounsaturated fatty acids & $38-45$ & $17-26$ & $56-65$ & $15-26$ & $56-87$ & $7-10$ & 24 & $30-32$ \\
Oleic acid C18:1n-9 & $36-44$ & $17-26$ & $55-62$ & $15-25$ & $55-83$ & $5.5-7.5$ & 21 & $16-20$ \\
Polyunsaturated fatty acids & $9-12$ & $54-72$ & $26-32$ & $62-70$ & $4-22$ & $2-4$ & $2-4$ & $18-20$ \\
Linoleic acid C18:2n-6 & $9-12$ & $50-62$ & $18-22$ & $62-70$ & $3-21$ & $<2.5$ & $1-2$ & $16-18$ \\
Alpha-linolenic acid C18:3n-3 & $<0.5$ & $4-10$ & $8-10$ & $<0.2$ & $<1$ & $<1$ & $1-2$ & $1-2$ \\
\hline
\end{tabular}

The possible alternatives to palm oil use in the food industry are the following [19]: (1) saturated animal fats, solid or semi-solid at room temperature, such as butter, lard or tallow: they have been gradually eliminated or substituted for their unfavourable health consequences; (2) saturated vegetable fats, solid at room temperature, such as cocoa butter (the most expensive fat), coconut and palm kernel: their use is limited owing to their correlation with increased plasmatic low-density lipoprotein (LDL) cholesterol levels; (3) other vegetable oils, rich in mono/polyunsaturated fats and fluid at room temperature, from fruits (olives), seeds (sunflowers), legumes (peanuts, soy and especially rapeseed) and grains (corn, rice), despite their nutritional qualities, they are disadvantageous in industrial use, owing to both their costs and their limited shelf life.

In conclusion, the substitution of saturated fats with unsaturated ones could be favourable from a nutritional viewpoint, but it involves decreases in crunchiness, palatability and some preservation properties, causing a series of disadvantages, especially in the preparation of bakery products. It is 
extremely important to recommend that the consumer pay attention to what is reported on the product's label: the use of palm oil in processed products is often linked to other ingredients, such as animal and vegetable fats. The standards for food labelling require information about the ingredients but not their precise quantities. Generally, however, nutritional labels report information on the content of saturated fats.

\section{Dietary Fats: Nutritional Recommendations}

Currently, nutritional recommendations suggest that fat intake should not exceed $30-35 \%$ of total calories, with a maximum of $10 \%$ from saturated fats. US guidelines for 2015 to 2020 define the target range of fat intake as between 30 and $40 \%$ of calories in early childhood and between 25 and 35\% starting at the age of 4 years, keeping the consumption of saturated fats under $10 \%$ of total calories [20].

In 2011, the French Agency for Food, Environmental and Occupational Health \& Safety (ANSES) stated that there is no evidence of benefits associated with fat consumption of less than $35 \%$ of total calories; furthermore, the risk associated with a fat consumption of up to $40 \%$ of calories has not been clearly documented [3].

In 2012, the Nordic (Scandinavian) Nutrition Recommendation raised the maximum value of acceptable lipids intake to $40 \%$ and stated that a level of fat consumption below $20 \%$ of total energy would increase the risk of low absorption of other macro- and micronutrients. The limit for saturated fats remains unchanged at $10 \%$ [21].

In 2014, the Italian Society of Human Nutrition (SINU) compiled the fourth revision of the Dietary Reference Values (Livelli di Assunzione di Riferimento di Nutrienti ed energia per la popolazione italiana (LARN)) for the Italian population, defining an interval of $20-35 \%$ of calories from fat as a benchmark for maintaining one's health without compromising the adequate absorption of essential fatty acids and fat-soluble vitamins. In particular, fat intake should not exceed $35-40 \%$ of total calories in children up to 3 years old, with a maximum $10 \%$ of calories from saturated fat for all age ranges [17]. The INRAN-SCAI 2005-2006 survey, the most recent investigative nutritional sample of the Italian population, shows that both total and saturated fat intake are slightly above the recommended levels ( $36 \%$ for total fats, $11 \%$ for saturated fats) in children between 3 and 18 years old [22]. The intake of saturated fats from foods containing palm oil in Italy was recently better defined by the Italian Institute of Health, reworking data supplied by INRAN-SCAI. According to this document, the absorption of saturated fatty acids from palm oil in foods is higher during breastfeeding and weaning [4]. Moreover, bakery products represent significant sources of saturated fats from palm oil, especially in younger children. This document also shows that the primary nutritional source of saturated fats in Italy is dairy, followed by oils (mainly olive oil, whose consumption should not, however, be reduced), fresh and processed meats and, lastly, baked goods [23].

When recommendations are compared with consumption, the actual Italian diet does not seem well balanced: smoked meats are eaten four times a week instead of twice a week; the amount of milk and yogurt is less than the recommended amount, while cheese consumption is higher than the desirable level. Moreover, legumes are almost absent. Therefore, it would be advisable to raise the intake of some products such as legumes, milk and yogurt in place of red meat, processed meat and cheeses. These changes could reduce the proportions of both total fat and saturated fat in the diet, decreasing them from 36 to $34 \%$ and from 11 to $10 \%$ of total calories, respectively, and would also diminish the level of salt consumption [3].

\section{Palm Oil and Saturated Fatty Acids: Effects on Children}

\subsection{The First Six Months of Life}

Dietary fats represent the main energy source during the first years of life, and they perform a crucial role in nurslings' growth and development, especially for premature neonates, because they are among the constituents of the nervous and retinal tissue. 
The newborn must immediately switch the main source of calories form glucose (placenta) to fats (breast milk) [24]. The composition of human milk is adapted to the needs of newborns and thus represents the gold standard on which to base infant formulas. In the absence of breast milk, formulas play a crucial role in ensuring the correct intake of nutrients.

In human milk, unsaturated fatty acids, including optimal percentages of essential fatty acids $(\alpha$-linolenic and linoleic), are more prevalent than saturated fatty acids. Saturated fatty acids, $50 \%$ of which consist of palmitic acid, account for $40 \%$ of total fat. Moreover, the particular stereospecific distribution of the different fatty acid triglycerides guarantees advantageous absorption. The differences between breast milk versus bovine milk are essentially qualitative; this is the reason why bovine milk is enriched with oleic acid and saturated lauric, myristic and palmitic acids [24]. In breast milk, palmitic acid is esterified at the sn-2 position, while in formulas it is often found in the sn- 1 and sn-3 positions, leading to less absorption and more solid faeces, which are typical in artificial breastfeeding.

Vegetal oils that are rich in saturated fatty acids, including some tropical oils (such as palm and coconut oils), are used for formulas in order to increase their energetic value [25]. In addition, the inter-esterification process induces favourable effects in infant formula, as the absorption of palmitic acid increases [25]. Recently, Sanders has demonstrated that palmitic acid in sn-2 can reduce postprandial lipemia, confirming the joint FAO/WHO study of $2008[8,26]$. A valid nutritional alternative for premature newborns, in the absence of breast milk, is the human milk bank, which has been shown to be a better alternative than formula milk.

\subsection{Six Months-Two Years}

Weaning is an important dietary change: the caloric contribution of lipids decreases from 50 to $35-40 \%$ at 24 months owing to a progressive increase in the amount of carbohydrates, which will continue into adulthood [27]. To date, there is no evidence of any link between dietary fat consumption before 2 years of age and later health conditions, particularly for non-transmissible chronic pathologies such as diabetes, metabolic syndrome or cardiovascular disease [28]. It is difficult, however, to determine the specific metabolic effects of a particular fatty acid and how much it influences the lipid profile in subsequent life phases. It is still difficult to understand the roles of various factors (i.e., gender, degree of excessive weight, distribution of body fat, level of motor activity, composition of macronutrients in the diet) on the optimal dietary lipid profile [29].

\subsection{Three Years-Eighteen Years}

From 3 years old onwards, the nutritional recommendations regarding fats are the same as those for adults. It is necessary to pay greater attention to one's lifestyle during these years, as the consumption of baked goods, snacks, cookies and chips is especially widespread in this age range [4]. Desserts and other such products contain refined oils, enhanced flours, chemical yeast, synthesized vitamins, sugars, high salt content, toxic products deriving from high-temperature cooking, and palm oil as well. This is the reason why palm oil cannot be considered the only culprit for the ill health effects of this junk food [30].

\section{Palm Oil and Saturated Fatty Acids: Different Metabolic Aspects of Health Risks}

\subsection{Effects on the Lipid Profile}

In the 1970s, the Seven Countries Study showed that the dietary consumption of saturated fats correlated to total cholesterolaemia and LDL, known factors in coronary risk [29]. Subsequent studies confirmed the connection between the levels of saturated fats and an increase in LDL cholesterol. The fatty acid composition of palm oil consists of high amounts of palmitic but also oleic acid. Consumption of oleic acid is considered as healthy. On the contrary, due to the fact that palm oil contains palmitic acid, which is a saturated fatty acid, it was extrapolated that palm oil should give rise 
to elevated total cholesterol and LDL cholesterol levels. However, the effects of palm oil on the lipid profile emerge from a meta-analysis of studies on the replacement of palm oil with mono-unsaturated fatty acids, polyunsaturated fats, myristic and lauric acid or trans-unsaturated fats: such substitutions do not induce variations in the LDL/HDL ratio [31]. The effect of palm oil on LDL cholesterolaemia seems to be considerably less than expected [32]. In conclusion, palm oil does not exert significant effects on the lipid profiles of young people or of people with normal cholesterolaemia.

\subsection{Correlations with Cardiovascular Diseases}

The guidelines suggest that saturated fat consumption be restricted to $10 \%$ of total calories. However, there is no scientific evidence that supports the real benefits of such a limit for the reduction of cardiovascular disease onset; it is still controversial [33]. A meta-analysis that focused on the relationship between saturated fats and cardiovascular risk did not identify any significant link [34]. It must be considered that cardiovascular disease development is multifactorial; therefore, it is difficult to understand the real role played by palm oil alone. Further studies on this potential risk are needed before drawing any conclusion.

\subsection{Oncological Risk}

The implications of palm oil use for oncological risk are not well known. The consumption of palm oil does not have a relevant impact on the risk of cancer [35]. Protective effects in relation with free radicals and anti-inflammatory action are also carried out by micronutrients, such as carotenoids, tocopherol, and tocotrienols, which are abundant in palm oil. Nevertheless, these compounds are absent in the palm oil usually used in the food industries in Europe. In conclusion, there is no evidence that standard consumption of palm oil in packaged foods plays a relevant role in increasing or decreasing the risk of cancer.

\subsection{Correlation with Obesity}

A recent study (LIPOGAIN) $[36,37]$ conducted on young, healthy, average-weight and slightly overweight subjects (Body mass index (BMI) $18-27 \mathrm{~kg} / \mathrm{m}^{2}$ ) highlights that the consumption of desserts prepared with palm oil causes a more atherogenic lipoprotein profile, a doubling of visceral fat and a significant increase of hepatic steatosis compared with the use of sunflower oil.

Such effects are probably connected with the consumption of fatty acids in general and not palm oil in particular, as similar results were observed with the use of butter in the place of palm oil [38]. However, definitive data in this regard do not exist in the literature [39].

\subsection{Correlation with Mortality Rate}

Recently, the scientific literature has paid attention to the relationship between saturated fat in diets and the mortality rate. According to a meta-analysis published in 2015 [12], the correlation between the consumption of saturated fats and all-cause mortality is zero. This consideration is confirmed by the PREDIMED study [40] conducted in a Mediterranean population at high cardiovascular risk. Unsaturated trans fats are the only fatty acids associated with an increased risk. In literature, different studies have evaluated the effect of various dietary fats on coronary mortality: in particular, in 2016 The NutriCODE group showed that a favourable impact $(-11 \%)$ on coronary mortality would be obtained by adequately increasing polyunsaturated-fat omega- 6 consumption, while the reduction of saturated fats within 10\% indicated by the guidelines would only translate to a reduction of $1 \%$ in the same coronary mortality. On a global scale, the reduction of saturated fats would produce results of modest importance [41]. The evaluation of the effects of palm oil on cardiovascular health and on all-cause mortality is more complex for the lack of specific data. The only relevant indirect data is the absence of correlation between the levels of palmitic acid absorption and coronary risk in a study of American nurses, at least for consumption up to $10 \%$ of total calories $[42,43]$. 


\section{False Myths}

After careful evaluation of the literature, we reviewed the portrayal of palm oil role in mass media. Biscuit packaging seems to project the notion of better quality by quite simply adding the label "without palm oil", suggesting that the absence of palm oil makes any food more desirable and safer for one's health. This conception a mistake. To date, there is no evidence that palm oil is a threat to be avoided; it is more relevant to understand the amounts written on the label, paying attention to the quantity of saturated fats contained in the food, rather than which fat is used. Eliminating palm oil does not guarantee the greater quality of the product. Therefore, it is necessary to debunk some myths and state some truths.

It is false that palm oil is dangerous for one's health. The balance between saturated fatty acids and polyunsaturated fats does not make it more damaging than other fats. The warning to not exceed total saturated fat limits remains valid [3].

It is false that palm oil is especially bad for children. Palmitic acid is fundamental in infantile nutrition [44-47].

Regarding the fact that palm oil contains toxic substances, it is true that according to the EFSA, toxic substances like GE, 2-MCPD and 3-MCPD can be found in palm oil. These contaminants derive from the transformation processes used: they are not part of the oil's makeup, but rather consequences of production process errors [1].

It is false that substituting palm oil with other oils is an advantage for the consumer. It depends on the fat with which it is substituted and on the total percentage of saturated fats contained in the product [3].

Moreover, it is only partially true that palm oil is bad for the environment. Palm oil is one of the most profitable resources of tropical regions, especially in Malaysia and Indonesia, allowing for economic development. However, environmental damage does exist: from 1990 to 2014, Indonesia lost an extended forestland area with considerable damages inflicted by deforestation. Therefore, in 2013 The Palm Oil Innovations Group set the goal of improve respect for the environment, avoiding deforestation and mistreatment of workers [48].

\section{Conclusions}

Palm oil is a widely used ingredient in the food industry. It represents a significant source of saturated fatty acids, to which scientific evidence attributes negative health effects when used in excess, especially with regards to cardiovascular diseases. They are contained in palm oil added to food during industrial transformations, but they are also present in other foods that naturally contain them (milk and its derivatives, eggs, meat). The required intake of fatty acids is greatest during the first few years of life and decreases with age. However, the consumption of saturated fats in the western population is higher than the suggested amount for the prevention of cardiovascular diseases, especially in children from 3 to 10 years of age.

To date, there is no evidence of harmful effects of palm oil on the health of children; in fact, palmitic acid has been to be necessary in the first years of life, as it is one of the main components of breast milk. Nevertheless, palm oil has possible ill health effects linked to its composition of fatty acids: its consumption is not correlated to risk factors for cardiovascular diseases in young people with a normal weight and cholesterol level; the elderly and patients with dyslipidaemia or previous cardiovascular events or hypertension are at a greater risk. Therefore, in the context of a balanced diet, rich in foods with normal saturated fatty acid content, it is necessary to repeat the importance of limiting the intake of saturated fats foods with a high saturated fat content, in order to respect the quantity recommended in the nutritional guidelines ( $10 \%$ maximum value of total calories).

Following the request on the eventual toxicity of palm oil as a dietary ingredient coming from the Directorate General for Hygiene in Food and Nutrition of the Ministry of Health, the Italian Ministry of Health has recently drawn up its scientific and technical opinion. The document concludes that no 
food or ingredient is definable as toxic in and of itself [4]. The eventual negative effects on health are to be measured on the basis of exposure levels.

In conclusion, the matter is not palm oil itself but the group of fatty-acid-rich foods to which it belongs. The most important thing is to consume no more than $10 \%$ of saturated fatty acids, regardless of their origin and regardless of one's age. Correct information based on a careful analysis of the scientific evidence, rather than a focus on a singular presumed culprit substance, should encourage better lifestyles.

Acknowledgments: This review, including the costs to publish in open access, was supported by a grant from the World Association of Infectious Diseases (WAidid).

Author Contributions: Lorenza Di Genova and Laura Cerquiglini wrote the first draft of the manuscript; Laura Penta revised the text; Anna Biscarini gave a support in the literature analysis; Susanna Esposito critically revised the text and made substantial scientific contributions. All the authors approved the final version of the manuscript.

Conflicts of Interest: The authors declare no conflict of interest.

\section{References}

1. EFSA. Panel on Contaminants in the Food Chain (CONTAM). Risks for human health related to the presence of 3- and 2-monochloropropanediol (MCPD), and their fatty acid esters, and glycidyl fatty acid esters in food. EFSA J. 2016, 14, 4426. [CrossRef]

2. Zlotkin, S.; Siekmann, J.; Lartey, A.; Yang, Z. The role of the Codex Alimentarius process in support of new products to enhance the nutritional health of infants and young children. Food Nutr. Bull. 2010, 31, S128-S133. [CrossRef] [PubMed]

3. Marangoni, F.; Galli, C.; Ghiselli, A.; Lercker, G.; La Vecchia, C.; Maffeis, C.; Agostoni, C.; Ballardini, D.; Brignoli, O.; Faggiano, P.; et al. Palm oil and human health. Meeting report of NFI: Nutrition Foundation of Italy symposium. Int. J. Food Sci. Nutr. 2017, 68, 643-655. [CrossRef] [PubMed]

4. Italian Ministry of Health. Parere dell'Istituto Superiore di Sanità Sulle Conseguenze per la Salute Dell'utilizzo Dell'olio di Palma Come Ingrediente Alimentare. 2016. Available online: http:/ /www.salute. gov.it/imgs/C_17_pubblicazioni_2481_allegato.pdf (accessed on 1 March 2018).

5. Hunter, J.E. Studies on effects of dietary fatty acids as related to their position on triglycerides. Lipids 2001, 36, 655-668. [CrossRef] [PubMed]

6. López-López, A.; López-Sabater, M.C.; Campoy-Folgoso, C.; Rivero-Urgell, M.; Castellote-Bargalló, A.I. Fatty acid and sn-2 fatty acid composition in human milk from Granada (Spain) and in infant formulas. Eur. J. Clin. Nutr. 2002, 56, 1242-1254. [CrossRef] [PubMed]

7. Innis, S.M. Palmitic Acid in Early Human Development. Crit. Rev. Food Sci. Nutr. 2016, 56, $1952-1959$. [CrossRef] [PubMed]

8. Sanders, T.A.; Filippou, A.; Berry, S.E.; Baumgartner, S.; Mensink, R.P. Palmitic acid in the sn-2 position of triacylglycerols acutely influences postprandial lipid metabolism. Am. J. Clin. Nutr. 2011, 94, 1433-1441. [CrossRef] [PubMed]

9. Filippou, A.; Teng, K.T.; Berry, S.E.; Sanders, T.A. Palmitic acid in the sn-2 position of dietary triacylglycerols does not affect insulin secretion or glucose homeostasis in healthy men and women. Eur. J. Clin. Nutr. 2014, 68, 1036-1041. [CrossRef] [PubMed]

10. Minihane, A.M.; Harland, J.I. Impact of oil used by the frying industry on population fat intake. Crit. Rev. Food Sci. Nutr. 2007, 47, 287-297. [CrossRef] [PubMed]

11. Mozaffarian, D.; Katan, M.B.; Ascherio, A.; Stampfer, M.J.; Willett, W.C. Trans fatty acids and cardiovascular disease. N. Engl. J. Med. 2006, 354, 1601-1613. [CrossRef] [PubMed]

12. De Souza, R.J.; Mente, A.; Maroleanu, A.; Cozma, A.I.; Ha, V.; Kishibe, T.; Uleryk, E.; Budylowski, P.; Schünemann, H.; Beyene, J.; et al. Intake of saturated and trans unsaturated fatty acids and risk of all-cause mortality, cardiovascular disease, and type 2 diabetes: Systematic review and meta-analysis of observational studies. Br. Med. J. 2015, 351, h3978. [CrossRef] [PubMed]

13. Mancini, A.; Imperlini, E.; Nigro, E.; Montagnese, C.; Daniele, A.; Orrù, S.; Buono, P. Biological and nutritional properties of palm oil and palmitic acid: Effects on health. Molecules 2015, 20, 17339-17361. [CrossRef] [PubMed] 
14. Pignitter, M.; Hernler, N.; Zaunschirm, M.; Kienesberger, J.; Somoza, M.M.; Kraemer, K.; Somoza, V. Evaluation of palm oil as a suitable vegetable oil for vitamin A fortification programs. Nutrients 2016, 8, 378. [CrossRef] [PubMed]

15. Dong, S.; Xia, H.; Wang, F.; Sun, G. The effect of red palm oil on vitamin A deficiency: A meta-analysis of randomized controlled trials. Nutrients 2017, 9, 1281. [CrossRef] [PubMed]

16. Loganathan, R.; Subramaniam, K.M.; Radhakrishnan, A.K.; Choo, Y.M.; Teng, K.T. Health-promoting effects of red palm oil: Evidence from animal and human studies. Nutr. Rev. 2017, 75, 98-113. [CrossRef] [PubMed]

17. SINU (Società Italiana di Nutrizione Umana). LARN_Livelli Di Assunzione Di Riferimento Di Nutrienti Ed Energia per La Popolazione Italiana. IV Revisione; Società Italiana di Comunicazione Scientifica e Sanitaria (SICS): Milano, Italy, 2014; pp. 1-655.

18. Arienti, G.; Brughenti, F.; Fidanza, F. Alimentazione e Nutrizione Umana. Ruoli e Richieste di Energia e Nutrienti Energetici; Idelson-Gnocchi: Napoli, Italy, 1998.

19. Sundram, K.; Hornstra, G.; von Houwelingen, A.C.; Kester, A.D. Replacement of dietary fat with palm oil: Effect on human serum lipids, lipoproteins and apolipoproteins. Br. J. Nutr. 1992, 68, 677-692. [CrossRef] [PubMed]

20. U.S. Department of Health and Human Services. 2015-2020 Dietary Guidelines for Americans. 2015. Available online: www.cnpp.usda.gov/2015-2020-dietary-guidelines-americans (accessed on 1 March 2018).

21. Nordic Nutrition Recommendations 2012. Integrating Nutrition and Physical Activity, 2012. Available online: www.norden.org/en/theme/nordic-nutrition-recommendation/nordic-nutrition-recommendations-2012 (accessed on 1 March 2018).

22. Sette, S.; Le Donne, C.; Piccinelli, R.; Arcella, D.; Turrini, A.; Leclercq, C.; INRAN-SCAI 2005-6 Study Group. The third Italian National Food Consumption Survey, INRAN-SCAI 2005-06-Part 1: Nutrient Intakes in Italy. Nutr. Metab. Cardiovasc. Dis. 2011, 21, 922-932. [CrossRef] [PubMed]

23. Sette, S.; Le Donne, C.; Piccinelli, R.; Mistura, L.; Ferrari, M.; Leclercq, C.; INRAN-SCAI 2005-06 Study Group. The third National Food Consumption Survey, INRAN-SCAI 2005-06: Major dietary sources of nutrients in Italy. Int. J. Food Sci. Nutr. 2013, 64, 1014-1021. [CrossRef] [PubMed]

24. Miniello, V.L.; Diaferio, L. Olio di palma: Dal biberon allo snack. Pediatr. Prev. Soc. 2015, 3, 7-20.

25. Carnielli, V.P.; Luijendijk, I.H.; van Beek, R.H.; Boerma, G.J.; Degenhart, H.J.; Sauer, P.J. Effect of dietary triacylglycerol fatty acid positional distribution on plasma lipid classes and their fatty acid composition in preterm infants. Am. J. Clin. Nutr. 1995, 62, 776-781. [CrossRef] [PubMed]

26. WHO. Interim Summary of Conclusions and Dietary Recommendations on Total Fat and Fatty Acids. In Joint FAO/WHO Expert Consultation on Fats and Fatty Acids in Human Nutrition; WHO HQ: Geneva, Switzerland, 10-14 November 2008.

27. Uauy, R.; Castillo, C. Lipid requirements of infants: Implications for nutrient composition of fortified complementary foods. J. Nutr. 2003, 133, 2962S-2972S. [CrossRef] [PubMed]

28. Agostoni, C.; Caroli, M. Role of fats in the first two years of life as related to later development of NCDs. Nutr. Metab. Cardiovasc. Dis. 2012, 10, 775-780. [CrossRef] [PubMed]

29. Maffeis, C.; Banzato, C.; Talamini, G. Obesity Study Group of the Italian Society of Pediatric Endocrinology and Diabetology. Waist-to-Height Ratio, a Useful Index to Identify High Metabolic Risk in Overweight Children. J. Pediatr. 2008, 152, 207-213. [CrossRef] [PubMed]

30. Kromhout, D.; Bloemberg, B.; Feskens, E.; Menotti, A.; Nissinen, A. Saturated fat, vitamin C and smoking predict long-term population all-cause mortality rates in the Seven Countries Study. Int. J. Epidemiol. 2000, 2 , 260-265. [CrossRef]

31. Fattore, E.; Bosetti, C.; Brighenti, F.; Agostoni, C.; Fattore, G. Palm oil and blood lipid-related markers of cardiovascular disease: A systematic review and meta-analysis of dietary intervention trials. Am. J. Clin. Nutr. 2014, 99, 1331-1350. [CrossRef] [PubMed]

32. Sun, Y.; Neelakantan, N.; Wu, Y.; Lote-Oke, R.; Pan, A.; van Dam, R.M. Palm oil consumption increases LDL cholesterol compared with vegetable oils low in saturated fat in a meta-analysis of clinical trials. J. Nutr. 2015, 145, 1549-1558. [CrossRef] [PubMed]

33. Nettleton, J.A.; Legrand, P.; Mensink, R.P. ISSFAL 2014 Debate: It Is Time to Update Saturated Fat Recommendations. Ann. Nutr. Metab. 2015, 66, 104-108. [CrossRef] [PubMed] 
34. Siri-Tarino, P.W.; Sun, Q.; Hu, F.B.; Krauss, R.M. Meta-analysis of prospective cohort studies evaluating the association of saturated fat with cardiovascular disease. Am. J. Clin. Nutr. 2010, 91, 535-546. [CrossRef] [PubMed]

35. American Cancer Society. Guidelines on Nutrition and Physical Activity for Cancer Prevention. 2016. Available online: http:/ / www.cancer.org/healthy / eathealthygetactive/acs-guidelines-nutrition-physicalactivity-cancer-prevention/nupa-guidelines-toc (accessed on 1 March 2018).

36. Iggman, D.; Rosqvist, F.; Larsson, A.; Arnlöv, J.; Beckman, L.; Rudling, M.; Risérus, U. Role of dietary fats in modulating cardiometabolic risk duringmoderate weight gain: A randomized double-bindoverfeeding trial (LIPOGAIN Study). J. Am. Heart Assoc. 2014, 3, e001095. [CrossRef] [PubMed]

37. Rosqvist, F.; Iggman, D.; Kullberg, J.; Cedernaes, J.; Johansson, H.E.; Larsson, A.; Johansson, L.; Ahlström, H.; Arner, P.; Dahlman, I.; et al. Overfeeding polyunsaturated and saturated fat causes distinct effects on liver and visceral fat accumulation in humans. Diabetes 2014, 63, 2356-2368. [CrossRef] [PubMed]

38. Bjermo, H.; Iggman, D.; Kullberg, J.; Dahlman, I.; Johansson, L.; Persson, L.; Berglund, J.; Pulkki, K.; Basu, S.; Uusitupa, M.; et al. Effects of n-6 PUFA compared with SFAs on liver fat, lipoproteins and inflammation in abdominal obesity: A randomized controlled trial. Am. J. Clin. Nutr. 2012, 95, 1003-1012. [CrossRef] [PubMed]

39. Teng, K.T.; Chang, C.Y.; Chang, L.F.; Nesaretnam, K. Modulation of obesity-induced inflammation by dietary fats: Mechanisms and clinical evidence. Nutr. J. 2014, 13, 12-15. [CrossRef] [PubMed]

40. Guasch-Ferré, M.; Babio, N.; Martínez-González, M.A.; Corella, D.; Ros, E.; Martín-Peláez, S.; Estruch, R.; Arós, F.; Gómez-Gracia, E.; Fiol, M.; et al. Dietary fat intake and risk of cardiovascular disease and all-cause mortality in a population at high risk of cardiovascular disease. Am. J. Clin. Nutr. 2015, 102, 1563-1573. [PubMed]

41. Wang, D.D.; Li, Y.; Chiuve, S.E.; Stampfer, M.J.; Manson, J.E.; Rimm, E.B.; Willett, W.C.; Hu, F.B. Association of Specific Dietary Fats with Total and Cause-Specific Mortality. JAMA Intern. Med. 2016, 176, 1134-1145. [CrossRef] [PubMed]

42. Hu, F.B.; Stampfer, M.J.; Manson, J.E.; Ascherio, A.; Colditz, G.A.; Speizer, F.E.; Hennekens, C.H.; Willett, W.C. Dietary saturated fats and their food sources in relation to the risk of coronary heart disease in women. Am. J. Clin. Nutr. 1999, 6, 1001-1008. [CrossRef] [PubMed]

43. Wang, Q.; Afshin, A.; Yakoob, MY.; Singh, G.M.; Rehm, C.D.; Khatibzadeh, S.; Micha, R.; Shi, P.; Mozaffarian, D.; Global Burden of Diseases Nutrition and Chronic Diseases Expert Group (NutriCoDE). Impact of Nonoptimal Intakes of Saturated, Polyunsaturated, and Trans Fat on Global Burdens of Coronary Heart Disease. J. Am. Heart Assoc. 2016, 5. [CrossRef] [PubMed]

44. Delplanque, B.; Gibson, R.; Koletzko, B.; Lapillonne, A.; Strandvik, B. Lipid Quality in Infant Nutrition: Current Knowledge and Future Opportunities. J. Pediatr. Gastroenterol. Nutr. 2015, 61, 8-17. [CrossRef] [PubMed]

45. De Silva, A.; Jones, P.W.; Spencer, S.A. Does human milk reduce infection rates in preterm infants? A systematic review. Arch. Dis. Child. Fetal Neonatal Ed. 2004, 89, F509-F513. [CrossRef] [PubMed]

46. Cripps, R.L.; Martin-Gronert, M.S.; Ozanne, S.E. Fetal and perinatal programming of appetite. Clin. Sci. 2005, 109, 1-11. [CrossRef] [PubMed]

47. De Nisi, G.; Berti, M.; Malossi, R.; Pederzini, F.; Pedrotti, A.; Valente, A. Comparison of neonatal intensive care: Trento area versus Vermont Oxford Network. Ital. J. Pediatr. 2009, 14, 35-45. [CrossRef] [PubMed]

48. European Palm Oil Alliance. Available online: http://www.palmoilandfood.eu (accessed on 1 March 2018).

(C) 2018 by the authors. Licensee MDPI, Basel, Switzerland. This article is an open access article distributed under the terms and conditions of the Creative Commons Attribution (CC BY) license (http://creativecommons.org/licenses/by/4.0/). 